\title{
Analysis Tool Overhang in The Machine Cnc Et-242 on Surface Roughness With Variation of Feeding
}

\author{
F.Rahmadianto ${ }^{1}$, D. Hermawan ${ }^{2}$ \\ ${ }^{1}$ Department of Mechanical Engineering, National Institute of Technology, Malang, Indonesia \\ ${ }^{2}$ Department of Mechanical Engineering, University of Widyagama, Malang, Indonesia \\ Email: rahmadianto15@gmail.com
}

\begin{abstract}
Lathe is a process to get the shape of the cylindrical workpiece by rotating the workpiece on the spindle and moving the chisel towards the workpiece. To be able to screw the workpiece of the chisel should hang and extend from the turret. The length of the hanging chisel is called the tool overhang [1]. There is no definite hint of setting the tool overhang and only adjusted between the position of the turret and workpiece. In order to achieve a good surface roughness, usually the overhang tool is arranged to a minimum. In this study the independent variables used are the tool overhang $14 \mathrm{~mm}, 21$ $\mathrm{mm}, 28 \mathrm{~mm}, 35 \mathrm{~mm}$ and feeding mm rotation ${ }^{-1}, 0.25 \mathrm{~mm}$ rotation ${ }^{-1}, 0.35 \mathrm{~mm}$. rotation ${ }^{-1}$. The measured dependent variable is the surface roughness of the workpiece. From the results of testing and data analysis can be concluded that the tool overhang effect on the roughness of the workpiece surface results of the process of lathe in various variations of feeding (feeding). The longer the tool overhang and the greater the feeding motion will result in greater surface roughness. The lowest surface roughness was obtained from a $14 \mathrm{~mm}$ long overhang tool and feeding $0.15 \mathrm{~mm} \mathrm{rotation}^{-1}$.
\end{abstract}

Keywords Machine CNC ET-242, Surface Roughness, Feeding Variation

Paper type Research paper

\section{INTRODUCTION}

One of the most widely used machining processes is lathe. Lathe is a process to get the shape of the cylindrical workpiece by rotating the workpiece on the spindle and moving the chisel towards the workpiece. The lathe process has five basic elements: cutting speed, feeding speed, cutting depth, cutting time and speed of furious income [2]. It is also influenced by the chisel geometry as well as the workpiece materials used. The elements are combined to obtain good machining results. One of the criteria of good machining results is the surface roughness that corresponds to the desired one.

But often in the process of lathe less attention to the installation of chisels. To be able to screw the workpiece of the chisel should hang and extend from the turret. The length of the hanging chisel is called the tool overhang [1]. There is no definite hint of setting the tool overhang and only adjusted between the position of the turret and workpiece. To achieve good surface roughness, usually the overhang tool is managed to a minimum and max 1.5 times the height of the installed tool holder [3]. Overhang tool is reduced as much as possible to avoid the possibility of deflection chisel during the cutting process. If the deflection is too large then it can cause chatter and can damage both workpieces and chisels [4]. Chatter is the vibration that occurs when the chisel moves toward the workpiece on the cutting process. This vibration creates a wavy surface, causing the subsequent cutting process to experience varying loads. And when that happens, the loading variation worsens the existing vibration [1]. The overhang tool is included in the chisel variables affecting surface roughness at Hard Turning [5]. The overhang tool does not affect the measured cutting force [6].

Tool length is used as one of the research variables suspected as a chisel vibration source affecting the resulting surface finish roughness. The longer the tool length the surface roughness is also increasing, except for large cutting depths or using small chiseled corners of the radius combined with small cutting depths[7]. Short tool length produces poor surface roughness when combined with a small chisel corner radius while a long chisel reduces tool stiffness [8].

This research uses CNC ET-242 lathes, which is used for the process of lathe to the workpiece. With this, research was made to optimize the factors of lathe by using the Taguchi method. The Taguchi method is expected to increase mechanical properties by minimizing the effects of the cause of the change without eliminating the causes. The cause of that variation in the taguchi method is known by an uncontrollable factor [9]. The object of this study used medium steel carbon steel AISI 1045 [10], with chemical content $0,43-0,50 \% \mathrm{C}, 0,60-0,90 \% \mathrm{Mn}, 0,04 \% \mathrm{P}$, and $0,05 \% \mathrm{~S}$ Researchers use this steel, because the steel is often used in the existing process of scrubbing everyday. The purpose of this research is to see the effect of the change of surface roughness of workpiece with tool overhang and feeding which is varied by using two-way variance analysis model with two independent variables and one dependent variable, then some experimental factor observed will be reduced to fewer experiments compared with factorial design so that the cost is relatively smaller. 


\section{METHOD}

The workpiece used is AISI 1045 steel with diameter $30 \mathrm{~mm}$ and length $60 \mathrm{~mm}$, with the composition of data as follows:

1. Chemical Composition

Table 1. Chemical Composition

\begin{tabular}{|c|c|}
\hline \multicolumn{2}{|c|}{ CHEMICAL ANALYSIS } \\
\hline $\mathbf{C}$ & Carbon $0.43-0.50$ \\
\hline Mn & Manganese $0.60-0.90$ max \\
\hline $\mathbf{P}$ & Phosphorus 0.040 max \\
\hline $\mathbf{S}$ & Sulfur $0.050 \max$ \\
\hline
\end{tabular}

2. The Chisel Lathe

The chisel used is SECO TOOL carbide insertion straw type CCMT 120408 F2 TP30 with tool type SCACL $1212 \mathrm{M} 09$.

3. Cutting Fluid

Cutting fluid used is a type of water soluble oil made from mineral oil of Kutwell 40 brand.

4. Flow Chart of Research

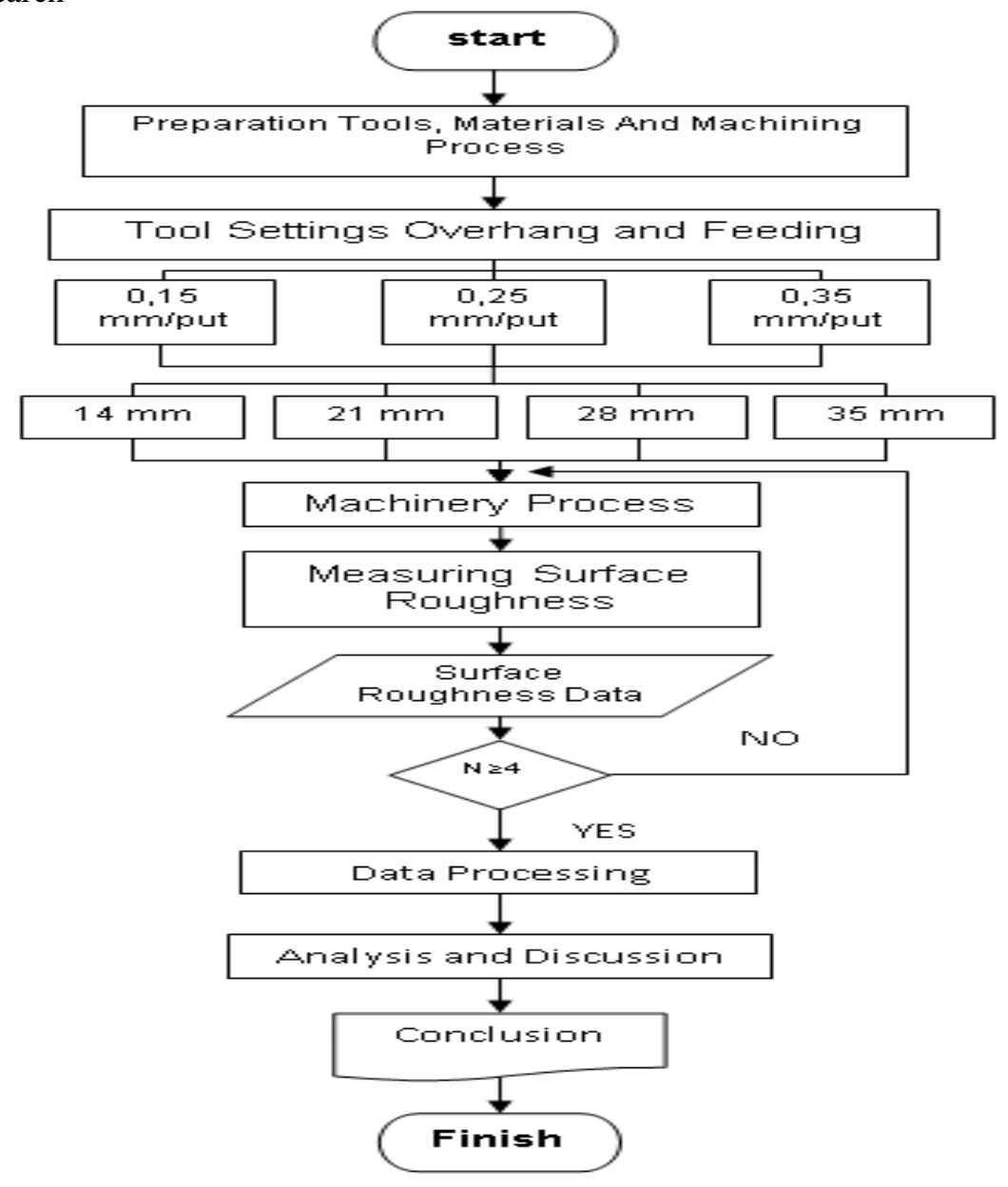

Fig. 1. Flow Chart of Research 
Analysis Tool Overhang in The Machine Cnc Et-242 on Surface Roughness With Variation of Feeding

\section{DISCUSSION}

From the results of surface roughness testing conducted with MITUTOYO Surface tester on the workpiece result of lathe, obtained the data in the table as follows

\begin{tabular}{|c|c|c|c|c|}
\hline factor & \multicolumn{4}{|c|}{ (feeding) } \\
\hline \multirow{17}{*}{ 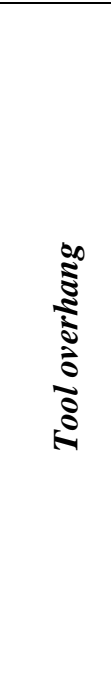 } & Level & $0,15 \mathrm{~mm} \cdot \mathrm{put}^{-1}$. & $0,25 \mathrm{~mm} \mathrm{put}^{-1}$ & $0,35 \mathrm{~mm} \cdot \mathrm{put}^{-1}$. \\
\hline & & 1.07 & 2.54 & 4.21 \\
\hline & $14 \mathrm{~mm}$ & 1.15 & 2.59 & 4.27 \\
\hline & $14 \mathrm{~mm}$ & 1.21 & 2.55 & 4.07 \\
\hline & & 1.09 & 2.50 & 3.97 \\
\hline & & 1.31 & 3.03 & 5.70 \\
\hline & & 1.57 & 3.21 & 5.98 \\
\hline & $21 \mathrm{~mm}$ & 1.39 & 3.11 & 5.85 \\
\hline & & 1.26 & 3.24 & 5.70 \\
\hline & & 1.84 & 3.69 & 6.23 \\
\hline & & 1.77 & 3.65 & 6.28 \\
\hline & $28 \mathrm{~mm}$ & 1.69 & 3.84 & 6.40 \\
\hline & & 1.63 & 3.85 & 6.63 \\
\hline & & 2.36 & 4.25 & 7.07 \\
\hline & $25 \mathrm{~mm}$ & 2.38 & 4.21 & 6.96 \\
\hline & $35 \mathrm{~mm}$ & 2.40 & 4.34 & 7.00 \\
\hline & & 2.53 & 4.18 & 7.19 \\
\hline
\end{tabular}

\section{Statistical Analysis}

Surface Roughness Surval Interval

This statistical analysis is used to determine the average estimator interval. Here is one example of calculations for specimen data with a $14 \mathrm{~mm}$ overhang tool and 0.15 motion feedmm.rot ${ }^{-1}$ :

1. Average surface roughness:

$$
\overline{\mathrm{x}}=\frac{\sum \mathrm{x}}{\mathrm{n}}=\frac{4,52}{4}=1,13
$$

2. Standard deviation $(\sigma)$.

$$
\sigma=\sqrt{\frac{\sum(\mathrm{x}-\overline{\mathrm{x}})^{2}}{\mathrm{n}-1}}=\sqrt{\frac{0,012}{3}}=0,063246
$$

3. Average Standard deviation $(\bar{\sigma})$.

$$
\bar{\sigma}=\frac{\sigma}{\sqrt{\mathrm{n}}}=\frac{0,063246}{\sqrt{4}}=0.031623
$$

4. The mean estimator interval of the specimen hardness.

Degree of fredom $(\mathrm{db})=\mathrm{n}-1=4-1=3$

By taking $\alpha=5 \%$,

$$
\begin{aligned}
& \text { then } t(\alpha / 2 ; d b)=(0.025 ; 3)=3,182 \\
& \qquad \bar{x}-t\left(\frac{\alpha}{2}, d b\right) \bar{\sigma}<\mu<\bar{x}+t\left(\frac{\alpha}{2}, d b\right) \bar{\sigma} \\
& 1.13-(3,182 \times 0,031623)<\mu<1.13+(3,182 \times 0,031623) \\
& 1,029<\mu<1,231
\end{aligned}
$$

From the calculation result, it can be said that the average estimation interval of hardness of specimen with tool overhang $14 \mathrm{~mm}$ and feeding motion $0.15 \mathrm{~mm}^{-r^{-1}}{ }^{-1}$ is between $1.029 \mu \mathrm{m}$ to $1,231 \mu \mathrm{m}$, with confidence level $95 \%$. In the same way it can be determined the interval estimator of the mean of hardness of specimen with tool overhang and other variation of eating motion is shown in the following table: 
TABLE 2. INTERVAL ESTIMATORS AVERAGE SURFACE ROUGHNESS

\begin{tabular}{|c|c|c|c|c|}
\hline Factor & & & (feeding) & \\
\hline \multirow{5}{*}{ 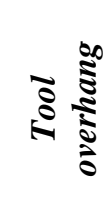 } & Level & $0,15 \mathrm{~mm} \cdot \mathrm{rot}^{-1}$. & $0,25 \mathrm{~mm} \cdot \operatorname{rot}^{-1}$ & $0,35 \mathrm{~mm} \cdot \mathrm{rot}^{-1}$. \\
\hline & $14 \mathrm{~mm}$ & $1.029<\mu<1,231$ & $2,486<\mu<2,603$ & $3,914<\mu<4,345$ \\
\hline & $21 \mathrm{~mm}$ & $1,166<\mu<1,598$ & $2,995<\mu<3,300$ & $5,593<\mu<6,022$ \\
\hline & $28 \mathrm{~mm}$ & $1,586<\mu<1,878$ & $3,594<\mu<3,920$ & $6,101<\mu<6,668$ \\
\hline & $35 \mathrm{~mm}$ & $2,295<\mu<2,539$ & $4,134<\mu<4,355$ & $6,895<\mu<7,215$ \\
\hline
\end{tabular}

\section{VARIAN ANALYSIS}

From the result of measurement of surface roughness obtained, two way analysis of variance to determine whether there is influence of variation of tool overhang and feeding (feeding), and their interaction with surface roughness of workpiece result of lathe.

1. The Total Amount og Treatment

$$
=174,94
$$

2. The sum of Squares throughout treatment

$$
\sum_{i=1}^{r} \sum_{j=1}^{c} \sum_{k=1}^{t} Y_{i j k}^{2}=807,9514
$$

3. Correction Factor (FK)

$$
\mathrm{FK}=\frac{\left[\sum_{\mathrm{i}=1}^{\mathrm{r}} \sum_{\mathrm{j}=1}^{\mathrm{c}} \sum_{\mathrm{k}=1}^{t} \mathrm{Y}_{\mathrm{ijk}}\right]^{2}}{\mathrm{rct}}=\frac{174,94^{2}}{48} 637,5834
$$

4. The sum of the total Squares (JKT)

$$
\mathrm{JKT}=\sum_{\mathrm{i}=1}^{\mathrm{r}} \sum_{\mathrm{j}=1}^{\mathrm{c}} \sum_{\mathrm{k}=1}^{t} \mathrm{Y}_{\mathrm{ijk}}{ }^{2}-\mathrm{FK}=807,9514-637,5834
$$

$\mathrm{JKT}=170,368$

5. The sum of the total Squares treatment (JKP)

$$
\mathrm{JKP}=\frac{\sum_{\mathrm{i}=1}^{\mathrm{r}} \sum_{\mathrm{j}=1}^{\mathrm{c}} \mathrm{Y}_{\mathrm{ij}}{ }^{2}}{\mathrm{t}}-\mathrm{FK}=\frac{3230,11}{4}-637,5834=169,9441
$$

6. The sum of the total Squares of influence A (JKA)

$$
\mathrm{JKA}=\frac{\sum_{\mathrm{i}=1}^{\mathrm{r}} \mathrm{Y}_{\mathrm{i}}^{2}}{\text { c.t }}-\mathrm{FK}==25,03974
$$

7. The sum of the total Squares of influence B (JKB)

$$
\mathrm{JKB}=\frac{\sum_{\mathrm{j}=1}^{\mathrm{c}} \mathrm{Y}_{\mathrm{j}}{ }^{2}}{\text { r.t }}-\mathrm{FK}=140,866
$$

8. The sum of the squares of the effects of interactions $A$ and $B(J K A B)$

$$
\mathrm{JKAB}=\mathrm{JKP}-\mathrm{JKA}-\mathrm{JKB}=4,038371
$$

9. The sum of the squares of the error (JKG)

$$
\mathrm{JKG}=\mathrm{JKT}-\mathrm{JKA}-\mathrm{JKB}-\mathrm{JKAB}=0,42385
$$

10. The square of influence $A\left(\mathrm{~S}_{\mathrm{A}}^{2}\right)$

$$
\mathrm{S}_{\mathrm{A}}{ }^{2}=\frac{\mathrm{JKA}}{\mathrm{r}-1}=\frac{25,03974}{3}=8,346581
$$

11. The Square of influence $B\left(\mathrm{~S}_{\mathrm{B}}{ }^{2}\right)$ 
Analysis Tool Overhang in The Machine Cnc Et-242 on Surface Roughness With Variation of Feeding

$$
\mathrm{S}_{\mathrm{B}}^{2}=\frac{\mathrm{JKB}}{\mathrm{c}-1}=\frac{140,866}{2}=70,43301
$$

12. The square is the interaction effect of $\mathrm{A}$ and $\mathrm{B}\left(\mathrm{S}_{\mathrm{AB}}{ }^{2}\right)$

$$
\mathrm{S}_{\mathrm{AB}}^{2}=\frac{\mathrm{JKAB}}{(\mathrm{r}-1)(\mathrm{c}-1)}=\frac{4,038371}{3.2}=0,673062
$$

13. Squares middle of error $\left(S^{2}\right)$

$$
\mathrm{S}^{2}=\frac{\mathrm{JKG}}{\mathrm{r} . \mathrm{c}(\mathrm{t}-1)}=\frac{0,42385}{4 \cdot 3 \cdot 3}=0,011774
$$

14. $\mathrm{F}_{\text {count }}$ influence $\mathrm{A}$

$$
F_{\text {count }} A=\frac{S_{A}{ }^{2}}{S^{2}}=\frac{8,346581}{0,011774}=708,9227
$$

15. $\mathrm{F}_{\text {count }}$ influence $\mathrm{B}$

$$
F_{\text {count }} B=\frac{S_{B}{ }^{2}}{S^{2}}=\frac{70,43301}{0,011774}=5982,278
$$

16. $\mathrm{F}_{\text {count }}$ the influence of the interaction of $\mathrm{A}$ and $\mathrm{B}$

$$
F_{\text {count }} A B=\frac{S_{A B}^{2}}{S^{2}}=\frac{0,673062}{0,011774}=57,16698
$$

TABLE 3. OF TWO-WAY VARIANT ANALYSIS

\begin{tabular}{lllccc}
\hline Sources of Diversity & Db & \multicolumn{1}{c}{ JK } & KT & F count & F table \\
\hline Tool overhang & 3 & 25,03974 & 8,346581 & 708,9227 & 2,872 \\
Feeding & 2 & 140,866 & 70,43301 & 5982,278 & 3,266 \\
Interaction & 6 & 4,038371 & 0,673062 & 57,16698 & 2,542 \\
Error & 36 & 0,42385 & 0,011774 & & \\
Total & 47 & & & & \\
\hline
\end{tabular}

Information :
A : Tool overhang
$\mathrm{B}$ : feeding

Based on the results of the calculations shown in the table above can be drawn the following conclusions:

a. $\quad \mathrm{F}_{\text {count }}>\mathrm{f}_{\text {table, }}$, then $\mathrm{Ho}^{1}$ is rejected and $\mathrm{H}^{1}{ }^{1}$ accepted. This shows that there is a real effect on the overhang tool change (factor A) on the roughness of the workpiece surface with a $95 \%$ confidence level

b. $\quad \mathrm{F}_{\text {count }}>\mathrm{f}_{\text {table, }}$, then $\mathrm{Ho}^{2}$ is rejected and $\mathrm{H}^{2}$ accepted. This shows that there is a real effect on feeding changes (factor B) on the roughness of the workpiece surface with a $95 \%$ confidence level

c. $\quad \mathrm{F}_{\text {count }}>\mathrm{f}_{\text {table }}$, then $\mathrm{Ho}^{3}$ is rejected and $\mathrm{H}^{3}$ accepted. This shows that there is a real effect on the interaction of overhang and feeding tool (AB factor) to the roughness of the workpiece surface with a $95 \%$ confidence level

\section{Analysis Of Linier Regression}

From the surface roughness data obtained can be done regression analysis. For regression equations tool overhang of surface roughness is done for each feeding variation. Regression equation used in this research is model of linear equation, with general equation as follows:

$$
\mathrm{Y}=\mathrm{a}+\mathrm{bx}
$$

For example, to find a linear regression, a regression calculation for surface roughness of the feeding variation is $0.15 \mathrm{~mm} \cdot \mathrm{rot}^{-1}$. 
TABLE 4. CALCULATION OF REGRESSION EQUATION RELATION TOOL OVERHANG 14 mm, 21 mm, 28 $\mathrm{mm}, 35 \mathrm{MM}$ WITH SURFACE ROUGHNESS FOR FEEDING $0.15 \mathrm{~mm} \cdot \mathrm{rot}^{-1}$.

\begin{tabular}{crrrr}
\hline No & \multicolumn{1}{l}{ X } & \multicolumn{1}{l}{ Y } & \multicolumn{1}{c}{$\mathbf{X}^{\mathbf{2}}$} & \multicolumn{1}{c}{ XY } \\
\hline 1 & 14 & 1.07 & 196 & 14.98 \\
2 & 14 & 1.15 & 196 & 16.1 \\
3 & 14 & 1.21 & 196 & 16.94 \\
4 & 14 & 1.09 & 196 & 15.26 \\
5 & 21 & 1.31 & 441 & 27.51 \\
6 & 21 & 1.57 & 441 & 32.97 \\
7 & 21 & 1.39 & 441 & 29.19 \\
8 & 21 & 1.26 & 441 & 26.46 \\
9 & 28 & 1.84 & 784 & 51.52 \\
10 & 28 & 1.77 & 784 & 49.56 \\
11 & 28 & 1.69 & 784 & 47.32 \\
12 & 28 & 1.63 & 784 & 45.64 \\
13 & 35 & 2.36 & 1225 & 82.6 \\
14 & 35 & 2.38 & 1225 & 83.3 \\
15 & 35 & 2.4 & 1225 & 84 \\
16 & 35 & 2.53 & 1225 & 88.55 \\
\hline$\Sigma$ & 392 & 26.65 & 10584 & 711.9 \\
\hline
\end{tabular}

Information : $\mathrm{X}=$ tool overhang $(\mathrm{mm})$

$\mathrm{Y}=$ Surface Roughness $(\mu \mathrm{m})$

Interaction relationship of overhang tool changes and feeding to surface roughness

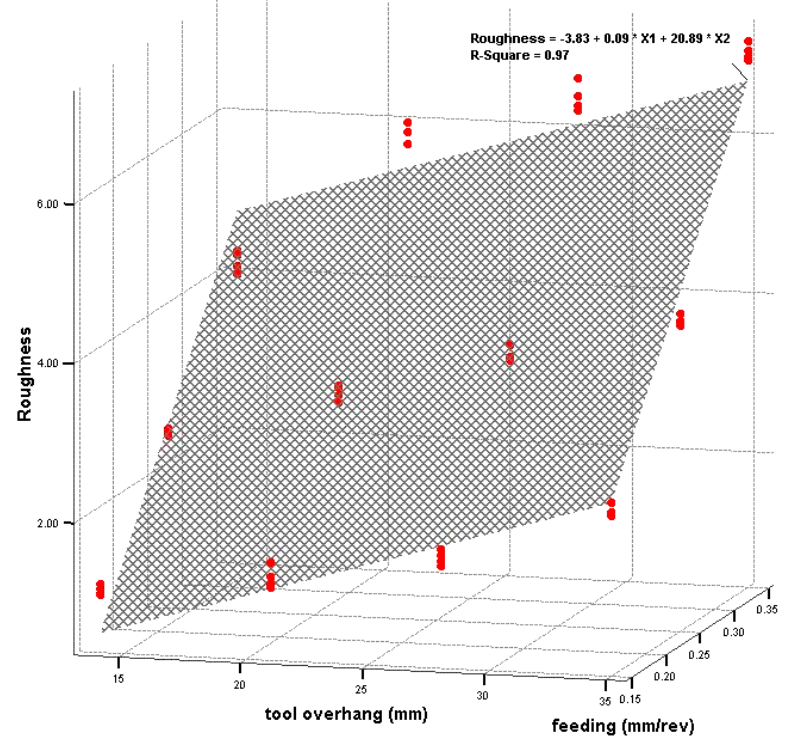

Fig. 2. Interaction relationship of overhang tool changes and feeding to surface roughness

In the picture above can be seen that the interaction tool overhang and eating motion will produce changes in the surface roughness that occurred. The longer the tool overhang and the greater the motion of feeding surface roughness that occurs also the greater.

Based on the analysis of variants on the tabell above, $\mathrm{F}$ arithmetic interaction tool overhang and motion eat larger than $\mathrm{F}$ table. This means that the interaction between the tool overhang with the motion to eat significantly affect the surface roughness that occurs with a confidence level of $95 \%$. The larger the feeding motion the surface roughness is also greater, this can be seen in equation (1) [11].

$$
\mathrm{Ra}=\frac{0.0321 \mathrm{f}^{2}}{\mathrm{r}_{\epsilon}}(\mathrm{mm})
$$




\section{Analysis Tool Overhang in The Machine Cnc Et-242 on Surface Roughness With Variation of Feeding}

A large feeding movement will leave a large feeding imprint, this can be overcome by the use of small feeding gear, where the feeding trace can be minimized by subsequent feeding. The larger the feeding motion causing the larger cutting force, this corresponds to equation (2).

$$
F_{c}=\text { f.a. } K s
$$

So that deflection is the result of increased cutting force due to increased feeding, and reduced stiffness due to the increasing length of tool overhang. This corresponds to the following equation (3)

$$
\delta=\frac{4 \cdot f \cdot a \cdot K s \cdot l^{3}}{E \cdot B \cdot H^{3}}(\mathrm{~mm})
$$

The deflection is an indication of the stiffness of the cutting system used. The greater the deflection the stiffening of the cutting system is weakened. The weakness of the cutting system affects the total surface roughness that occurs. As shown in the following equation [2].

$$
\mathrm{R}_{\mathrm{t}}=\mathrm{c}_{\mathrm{r}} \cdot \frac{\mathrm{f}^{2}}{8 \mathrm{r}_{\mathrm{e}}}(\mu \mathrm{m})
$$

Cr value will be smaller if the cutting system used (chisel) more rigid. So that the resulting surface roughness will be smaller with increasing stiffness of the cutting system used. Similarly, the resulting surface roughness will be greater if the stiffness of the cutting system used is weak.

\section{CONCLUSION}

Tool overhang effect on the roughness of the workpiece surface of the process of lathe in various variations of feeding (feeding). The longer the tool overhang and the greater the feeding motion will result in increasingly poor surface roughness. The lowest surface roughness was obtained from a $14 \mathrm{~mm}$ long overhang tool and feeding $0.15 \mathrm{~mm} \cdot \mathrm{rot}^{-1}$.

\section{REFERENCES}

[1] Zelinski,Peter.2005.The Overhang Effect.

[2] Rochim, Taufiq.1993. Proses Permesinan.Bandung: Penerbit ITB

[3] Sharma, PC.1983. A Text Book Of Production Engineering.New Delhi: S Chand \& Company Ltd.

[4] Drew,T Wayne. 1963. Machinery Repairman. http://metalworking.com/disort.php/Navy-Repairman-Manual-Chapter06.pdf

[5] Vernon,Aaron, Tugrul Ozel.2003.Factors Affecting Surface Roughness in Finish Hard Turning.New Jersey. www.soe.rutgers.edu/ie/research/working_paper/paper\%2003-104.pdf

[6] Failli, F, M. Beghini, G. Dini, M. Santochi, G. Tantussi.1998. A sensor integrated tool for two-components cutting force monitoring.Pisa: Department of Mechanical, Nuclear and Production Engineering, University of Pisa, Pisa,Italy. http://www2.ing.unipi.it/ dimnp/CD/supporto/pdf/failli_beghini_santochi_dini.pdf

[7] Thomas, M, Y Beauchamp, A Youssef, J Masounave. 1997. An Experimental design for surface roughness an build up edge formation in lathe dry turning. Montreal.

[8] Thomas, M, Y Beauchamp.2003. Statistical Investigation of modal parameters of cutting tool in dry turning.Quebec.

[9] Cooperrider, Bryan.1997.General Lathe Information. http://www.prl.stanford.edu/documents/obsolete/lathe.pdf

[10] Degarmo, Ernest P, JT Black, dan RA Kohser.1988. Material And Process In Manufacturing $7^{\text {th }}$ edition.New York: Macmillan Publishing Company

[11] Boothroyd, Geoffrey.1983. Fundamental Of Metal Machining And Machine Tool.Tokyo: McGraw Hill Book Co. 